\title{
Quality of Life in Women with Deep Endometriosis: A Cross-Sectional Study
}

\section{Qualidade de vida de mulheres com endometriose profunda: Estudo de corte transversal}

\author{
Daniela Angerame Yela ${ }^{1}$ luri de Paula Quagliato ${ }^{10}$ Cristina Laguna Benetti-Pinto ${ }^{1[}$ \\ ${ }^{1}$ Department of Gynecology and Obstetrics, School of Medical \\ Sciences, Universidade de Campinas, Campinas, SP, Brazil \\ Address for correspondence Daniela Angerame Yela, MD, PhD, \\ Universidade de Campinas, Campinas, SP, 04111-070, Brazil \\ (e-mail: yela@unicamp.br).
}

Rev Bras Ginecol Obstet 2020;42(2):90-95.

\begin{abstract}
Keywords

- endometriosis

- quality of life

- pelvic pain

- dysmenorrhea
\end{abstract}

\section{Resumo}

received

August 21, 2019

accepted

January 13,2020
Objective To describe clinical and sociodemographic characteristics of women with deep infiltrating endometriosis (DIE) and assess their quality of life (QOL) during 6 months of medical treatment.

Methods A descriptive cross-sectional study of 60 women diagnosed with DIE either by surgery or image methods (ultrasound or magnetic resonance), who received clinical treatment for at least 6 months in the Universidade de Campinas, Campinas, state of São Paulo, Brazil. Both the SF-36 and the EHP-30 questionnaires were used to assess the quality of life.

Results The mean age of the patients was $37.7 \pm 6.0$ years old, with $50 \%$ presenting dysmenorrhea; $57 \%$ dyspareunia; and $50 \%$ chronic pelvic pain. The SF-36 and the EHP30 revealed impaired quality of life. In the SF-36, the worst domains were limitation due to emotional aspects $(40.2 \pm 43.1)$ and self-esteem and disposition $(46.1 \pm 24.8)$, whereas in the EHP-30 they were social well-being $(50.3 \pm 30.6)$; infertility $(48.0 \pm 36.3)$; and sexual intercourse $(54.0 \pm 32.1)$.

Conclusion Although clinically treated, women with deep endometriosis present impairment in different domains of quality of life regardless of the questionnaire used for evaluation.

Objetivo Descrever características clínicas e sociodemográficas de mulheres com endometriose profunda infiltrativa e avaliar sua qualidade de vida dentro de 6 meses de tratamento clínico.

Métodos Estudo de corte transversal descritivo com 60 mulheres em seguimento ambulatorial na Universidade de Campinas, Campinas, SP, Brasil, com endometriose profunda infiltrativa diagnosticada por cirurgia ou métodos de imagem (ultrassonografia ou ressonância magnética), em tratamento clínico há pelo menos 6 meses. Para avaliar a qualidade de vida, foram utilizados os questionários SF-36 e EHP-30.

Resultados A média etária das mulheres foi de 37,7 $\pm 6,0$ anos; $50 \%$ delas apresentaram dismenorreia, $57 \%$ dispareunia e $50 \%$ dor pélvica crônica. O SF-36 e o EHP-30 mostraram comprometimento da qualidade de vida destas mulheres. No SF-36, os 
Palavras-chave

- endometriose

- qualidade de vida

- dor pélvica

- dismenorreia piores domínios foram os aspectos emocionais $(40,2 \pm 43,1)$ e a autoestima e disposição $(46,1 \pm 24,8)$, enquanto que no EHP-30 foram o bem-estar social $(50,3 \pm 30,6)$, a infertilidade $(48,0 \pm 36,3)$ e as relações sexuais $(54,0 \pm 32,1)$.

Conclusão Embora tratadas clinicamente, as mulheres com endometriose profunda apresentaram comprometimento em diferentes domínios da qualidade de vida independente do questionário utilizado para avaliação.

\section{Introduction}

Endometriosis is characterized by the presence of endometriotic tissue beyond the uterine cavity, mainly in the ovaries and other pelvic organs. ${ }^{1}$ Women with endometriosis may be asymptomatic or may report symptoms of dysmenorrhea; deep dyspareunia; chronic pelvic pain; urinary pain or intestinal pain; and infertility. ${ }^{2}$

Although all types may cause pain, deep lesions are usually related to a more severe clinical status, impairing quality of life (QOL); daily work activities; social relationships; and frequently the fertility of these women. ${ }^{3-5}$ Studies report a reduction in $\sim$ $38 \%$ of the work productivity of these women, mainly attributed to pelvic pain. ${ }^{4}$ Furthermore, $~ 88 \%$ of these women had anxiety disorders or depression. ${ }^{6}$ The disease was also highly relevant in the area of human reproduction, since $50 \%$ of patients diagnosed with endometriosis had some fertility disorder, due to chronic inflammation and the formation of pelvic adhesions. $^{7}$

Studies have shown that endometriosis has a negative impact on QOL. ${ }^{4,8,9}$ However, with surgical and/or medical treatment, QOL is improved. ${ }^{10-14}$ The majority of studies in the literature did not evaluate women according to the disease stage, although few studies show a poorer QOL in later stages. ${ }^{15}$ In addition, women with chronic pain have a lower QOL due to both physical and psychological factors. $^{16,17}$ The literature also shows that pain reduction is generally not related to the improvement of psychological disturbances. ${ }^{18}$ A recent study with women with deep endometriosis has shown that it affects these women globally and that more studies are needed to better understand the whole context. ${ }^{19}$ Therefore, because endometriosis can negatively affect QOL, particularly in more advanced stages, the main goal of the present study is to assess QOL in women with deep infiltrating endometriosis (DIE).

\section{Methods}

A descriptive cross-sectional study was performed with 60 women undergoing medical treatment for at least 6 months at the Universidade de Campinas (UNICAMP, in the Portuguese acronym), Campinas, State of São Paulo, Brazil, for DIE, diagnosed surgically or by imaging (nuclear magnetic resonance imaging [NMRI] or transvaginal ultrasound with bowel preparation). Deep infiltrating endometriosis was characterized when imaging exams showed lesions in the retrocervical region (uterosacral ligaments and uterine torus), the vagina, the intestine (rectum, sigmoid, ileum and appendix), the bladder and the ureter. Women who were surgically diagnosed had performed the procedure for $>2$ years and had recurred from the injuries after surgery. Those included in the study were exclusively on drug treatment. Women with cognitive impairment, incapable of understanding the instruments, and women with other chronic diseases such as neoplasias; lower back pain; psychiatric disorders; rheumatologic diseases; among others that could impact the QOL, were excluded.

The diagnosis of DIE was considered surgical when a surgical description of deep endometriosis was presented along with a confirmatory anatomopathological report (20 women had surgical diagnosis). All of the women with surgical diagnosis were on hormonal treatment to prevent recurrence and to control pain. Clinical diagnosis was performed by transvaginal ultrasound with bowel preparation or NMRI (40 women had imaging diagnosis). The diagnosis of deep endometriosis established by imaging was performed through transvaginal sonography with bowel preparation or NMRI, always performed by the same expert during the diagnosis. All of the women had pain symptoms and 20 women had infertility, and at the time of the interview 9 were asymptomatic.

The variables analyzed were: QOL; age; color (white, nonwhite); school education (illiterate, elementary school level, high school level, university level); family income; professional activity (unemployed, employed); marital status (with a partner, without a partner); religion (atheist, catholic, protestant and other); number of pregnancies; parity; body mass index (BMI) (calculated by weight in kilograms divided by height in square meters, classified as underweight $<20 \mathrm{~kg} / \mathrm{m}^{2}$, normal 20 to $25 \mathrm{~kg} / \mathrm{m}^{2}$, overweight 25 to $30 \mathrm{~kg} / \mathrm{m}^{2}$, and obese $\geq 30 \mathrm{~kg} / \mathrm{m}^{2}$ ); treatment used, symptoms of endometriosis (dysmenorrhea, dyspareunia, chronic pelvic pain, pain to urinate and pain to defecate), smoker (yes or no), surgical history (any previous surgeries such as abdominal surgeries or cesareans). Treatments used for pain control were hormonal (progestin alone - 53 women, or combined oral contraceptives - 5 women) or non-hormonal (nonsteroidal anti-inflammatory agents - 2 women).

Pain symptoms were evaluated according to the pain visual analog scale (VAS) on a scale of 0 to 10 , where 0 represented absence of pain and 10 indicated maximum pain. Pain was classified as mild when the score was 1 to 3 , moderate when the score was 4 to 6 and severe when it was $>7 .^{20}$

To assess QOL, two questionnaires were used: the Endometriosis Health Profile Questionnaire (EHP-30) and the Short Form - 36 (SF-36). The EHP-30 questionnaire was developed 
by Jones et al, in $2001^{21}$ and was validated to Brazilian Portuguese in 2008 by Mengarda et al. ${ }^{22}$ It consists of 30 items covering five dimensions: pain; control and capacity to cope with the disease (hopelessness); emotional well-being; social support and self-image; and a modular questionnaire with 23 items distributed in six scales: sexual intercourse; work; doctor x patient relationship (medical profession); infertility; relationship with children and treatment. Each item is assessed on a 4-point scale (never $=0$, rarely $=1$, sometimes $=2$, many times $=3$, always $=4)$. Scoring is transformed into a 0 to 100 scale, where the lowest score means a better QOL.

The SF-36 questionnaire was developed by Ware et al in $1992^{23}$ and was validated to Brazilian Portuguese in 1999 by Ciconelli et al. ${ }^{24}$ It assesses 8 dimensions: functional aspects; physical aspects; pain; general health status; vitality; social aspects; emotional aspects; and mental health. It presents a final score of 0 to 100 , in which zero corresponds to a worse general health status and 100 to a better general health status. Among the eight scales, three (functional capacity, physical aspects and pain) correspond to the Physical Component Summary (PCS), and the Mental Component Summary (MCS )includes mental health scales, emotional and social aspects. Two of the scales (vitality and general health) do not correlate with either component. ${ }^{23}$

All of the participants in the study signed an informed consent agreement. The present study was approved by the Research Ethics Committee of the Institution (number: 43715915.4.0000.5404).

\section{Statistical Analysis}

To calculate the sample size, the method used to compare the average QOL score between 2 evaluations in a longitudinal study (before and after intervention) with a quantitative variable, was according to Browner et $\mathrm{al}^{25}$ setting the significance level of $\alpha$ or type I error at 5\% ( $\alpha=0.05)$ (or $95 \%$ confidence interval $[\mathrm{CI}]$ ), and sample power at $80 \%$ (or $20 \%$ type II error $[\beta=0.20]$ ), and obtaining the mean and standard deviation (SD) values of delta (difference of scores between before and after intervention) from a literature study. ${ }^{26}$ It was estimated that a sample of 63 women would be representative to compare the physical QOL score after 6 months of treatment, with a $5 \%$ significance level and $80 \%$ sample power.

Descriptive analysis expressed in relative frequencies was used for statistical analysis, for the categorical variables and for the continuous variables the analysis was expressed in mean and SD.

\section{Results}

We evaluated 60 women treated clinically, out of which 2 were excluded due to the use of anti-inflammatory treatment, leaving 58 women who underwent hormonal clinical treatment.

The mean age of the patients was $37.2 \pm 6.0$ years old (minimum: 26 years old and maximum: 49 years old); 55\% were nulliparous and $75 \%$ of the cases had already undergone previous surgery. Regarding clinical factors, 91\% were undergoing progestin treatment; $51 \%$ had chronic pelvic pain; $58 \%$ had dyspareunia; $53 \%$ had dysmenorrhea, $13 \%$ had pain on urination and $43 \%$ had pain when defecating (-Table 1). Regarding pain intensity, we observed that women reported scores of $7.5 \pm 4.9$ for dysmenorrhea, $7.4 \pm 4.9$ for dyspareunia, $7.2 \pm 4.4$ for chronic pelvic pain, $6.6 \pm 4.9$ for pain when defecating and $5.7 \pm 0.7$ for pain when urinating.

Table 1 Percentage distribution of women with deep infiltrating endometriosis according to sociodemographic and clinical characteristics $(n=58)$

\begin{tabular}{|c|c|}
\hline Characteristic & $n(\%)$ \\
\hline \multicolumn{2}{|l|}{ Color } \\
\hline White & $44(75.86)$ \\
\hline Non-white & $14(24.14)$ \\
\hline \multicolumn{2}{|l|}{ Marital status } \\
\hline With a partner & $37(63.79)$ \\
\hline Without a partner & $21(34.21)$ \\
\hline \multicolumn{2}{|l|}{ Profession } \\
\hline Employed & $15(25.86)$ \\
\hline Unemployed & $43(74.14)$ \\
\hline \multicolumn{2}{|l|}{ Education } \\
\hline Illiterate & $1(1.73)$ \\
\hline Elementary school level & $14(24.14)$ \\
\hline High school level & $28(48.27)$ \\
\hline University level & $15(25.86)$ \\
\hline \multicolumn{2}{|l|}{ Gestation } \\
\hline Nulliparous & $32(55.17)$ \\
\hline Multiparous & $26(44.83)$ \\
\hline \multicolumn{2}{|l|}{$\mathrm{BMI}\left(\mathrm{kg} / \mathrm{m}^{2}\right)$} \\
\hline$\leq 20$ & $4(6.89)$ \\
\hline $20-25$ & $24(41.39)$ \\
\hline $25-30$ & $16(27.58)$ \\
\hline$\geq 30$ & $14(24.14)$ \\
\hline \multicolumn{2}{|l|}{ Smoking } \\
\hline Yes & $5(8.63)$ \\
\hline No & $53(91.37)$ \\
\hline \multicolumn{2}{|l|}{ Previous surgery } \\
\hline Yes & $44(75.86)$ \\
\hline No & $14(24.14)$ \\
\hline \multicolumn{2}{|l|}{ Treatment } \\
\hline Progestin & $53(91.37)$ \\
\hline Estrogen with progestin & $5(8.63)$ \\
\hline \multicolumn{2}{|l|}{ Pain symptoms } \\
\hline Dysmenorrhea & $31(53.44)$ \\
\hline Chronic pelvic pain & $30(51.72)$ \\
\hline Dyspareunia & $34(58.62)$ \\
\hline Intestinal pain & $25(43.10)$ \\
\hline Urinary pain & $8(13.79)$ \\
\hline
\end{tabular}

Abbreviation: BMI, body mass index. 
Table 2 Descriptive analysis of questionnaire domains SF-36

\begin{tabular}{llll}
\hline Domains & $\boldsymbol{n}$ & mean & SD \\
\hline Functional capacity & 58 & 56.2 & 23.7 \\
$\begin{array}{l}\text { Limitation due to } \\
\text { physical aspects }\end{array}$ & 58 & 50.0 & 42.9 \\
Pain & 58 & 55.1 & 59.4 \\
General health status & 58 & 60.8 & 22.4 \\
Self-esteem and disposition & 58 & 46.1 & 24.8 \\
Social aspects & 58 & 57.8 & 29.5 \\
Limitation due to & 58 & 40.2 & 43.1 \\
emotional aspects & & & \\
Mental health & 58 & 51.1 & 24.0 \\
\hline
\end{tabular}

Abbreviation: SD, standard deviation.

The SF-36 exhibited median scores for all domains. The women had scores $\geq 50$ on average in the physical domains of the SF-36, such as functional capacity; limitation due to physical aspects; pain; and general health status. Psychological domains (self-esteem $46.1 \pm 24.8$; disposition and emotional aspects $40.2 \pm 43.1$ ) affected the QOL in these women more intensely; although other psychological domains, such as social aspects and mental health, scored $>50$ (-Table 2 ).

In the EHP-30, some questions from the domains work; children; sexual intercourse; doctor patient relationship; treatment and infertility were not answered by all of the women, because they did not feel empowered to respond (they had not experienced the questions asked or felt constrained in responding).

The EHP-30 showed a greater impairment in QOL in social domains (social well-being $50.3 \pm 30.6$; social support $48.0 \pm 36.2)$, capacity to cope with the disease $(44.7 \pm 33.7)$ and fertility $(48.0 \pm 36.3)$. These women had a good doctorpatient relationship $(18.1 \pm 23.8)$. Only 21 out of 58 women responded to the children domain, since these patients were either nulliparous or felt uncomfortable talking about the subject ( - Table 3 ).

Table 3 Descriptive analysis of questionnaire domains EHP-30

\begin{tabular}{llll}
\hline Domains & $\boldsymbol{n}$ & Mean & SD \\
\hline Pain & 58 & 40.4 & 31.1 \\
$\begin{array}{l}\text { Control and capacity to cope } \\
\text { with the disease }\end{array}$ & 58 & 44.7 & 33.7 \\
Social well-being & 58 & 50.3 & 30.6 \\
Social support & 58 & 48.0 & 36.2 \\
Self-image & 58 & 41.2 & 34.2 \\
Work & 47 & 27.5 & 31.4 \\
Children & 21 & 33.9 & 37.3 \\
Sexual intercourse & 52 & 54.0 & 32.1 \\
Doctor x patient relationship & 56 & 18.1 & 23.8 \\
Treatment & 51 & 35.3 & 31.1 \\
Infertility & 39 & 48.0 & 36.3 \\
\hline
\end{tabular}

Abbreviation: SD, standard deviation.

\section{Discussion}

Assessment of QOL, by applying questionnaires, allows the measuring of the general impact of chronic diseases, such as endometriosis, on the lives of women. Two questionnaires were used in the current study, generic and specific, the SF-36 and the EHP-30, respectively, to observe whether the results were similar. The decision to apply both questionnaires is based on the fact that both address physical (pain) and psychological aspects that can influence the QOL in women with a chronic disease. However, the EHP-30 addresses some specific aspects of endometriosis that affect the QOL of these women, such as their sexual function; the question of motherhood; the relationship between doctor and patient; and the treatment of the disease. A recent review shows that endometriosis affects negatively the QOL of women with endometriosis but there is still no consensus on what would be the best instrument to evaluate it. ${ }^{27}$

In a review published in 2017 that evaluated 26 studies on endometriosis and QOL, only one used the EHP-30 and SF-36 questionnaires. ${ }^{28}$ And recently, a Brazilian study addressed QOL in women with deep endometriosis using the two questionnaires. $^{18}$

Approximately half of the women in the study had good pain control, but those with this symptom had moderate to severe pain. Furthermore, on evaluation of their QOL, these women had better results in the physical domains than in the psychological domain. It is also important to highlight that these women had deep endometriosis. In the literature, studies usually do not assess QOL according to disease stage.

Studies in the literature have shown that women with a more severe pain level have a worse QOL, although physical QOL is only related to physical pain. According to models of mediation, increasing physical pain and difficulties in emotion regulation result in increased psychological stress, which is associated with deterioration in QOL. The main goal of the treatment is to reduce pain symptoms and improve QOL, decreasing the societal burden and health care costs related to endometriosis. ${ }^{27,29}$

A review of 18 articles published in the past 5 years showed that understanding by the part of family members and partners may help women cope with this disease. In addition, pharmacological and surgical treatment may contribute toward pain control. However, other alternatives have been associated with the therapeutic management of endometriosis, such as lifestyle changes; physical exercise; diet; and sleep. ${ }^{30}$

A Brazilian study was performed in 2008 to investigate the relationship between clinical aspects and QOL in a group of 130 women with endometriosis. Data was collected using the SF36 questionnaire, showing that patients with endometriosis had lower QOL scores than the general population. ${ }^{27}$

The term QOL should encompass three main dimensions: mental health; physical; and social functioning. Both questionnaires addressed these issues and apparently presented similar results. It has been observed that medical treatment helps a woman to improve in some items, since it was effective in pain control. Although management is not 
effective at obtaining an excellent QOL, it still exerts a significantly negative impact on QOL.

Studies have emphasized the central role of pain associated with endometriosis, which is negatively correlated with QOL; sexual functioning; quality of relationship with partner; mood; work; and social role functioning. Chronic pain may result in social isolation and can also negatively affect emotional well-being. Endometriosis is associated with psychological problems; anxiety; depression, and a weak capacity to cope with difficulty. It is noteworthy that there is a positive relationship between the level of anxiety symptoms and pain intensity. A decrease in the level of depressive symptoms is observed after pain treatment. ${ }^{28}$ Furthermore; it is worth mentioning that women with asymptomatic endometriosis may not report impairment of QOL and mental health. ${ }^{31}$ Another study showed greater improvement in physical domain scores than in those of mental domains for patients with deep endometriosis. ${ }^{11}$

In the SF-36 questionnaire, the domain due to emotional aspects and self-esteem/disposition had a mean score of 40.2 and 46.1, respectively, once again pointing to the mental health issue, which is not frequently addressed during medical consultations. Another Brazilian study of 128 women performed in 2007 suggested that psychological support with group intervention was a good adjunct to conventional treatment, since scores of pain and emotional aspects decreased. $^{32}$ A recent study shows that women with deep endometriosis have worse physical and mental QOL than women with rheumatoid arthritis. ${ }^{33}$

The limitation of the present study is not having included a control group in the analysis. The literature shows that medical or surgical treatment may improve pain over time. The QOL in a woman with deep endometriosis is still unsatisfactory and inferior in comparison to the QOL of the general population, since other aspects (psychological, social and sexual) are not addressed.

Some studies in the literature show an overall improvement in the QOL of clinically treated women with endometriosis. ${ }^{26,34}$ All of these studies were prospective and women were followed for at least 1 year. This makes us infer whether medical care could help improve the psychological aspects of QOL. The fact that our study evaluates women at just one moment of their lives may not reflect all aspects of QOL and, therefore, these women present a deterioration of their QOL mainly in relation to psychological aspects.

\section{Conclusion}

Both questionnaires used in the current study addressed these issues and apparently produced similar results. It has been observed that medical treatment can help women improve in some aspects. Management is not effective at obtaining an excellent QOL, as endometriosis still exerts a significantly negative impact on a patient's QOL.

\section{Contributors}

All of the authors contributed with the project and data interpretation, the writing of the article, the critical review of the intellectual content, and with the final approval of the version to be published.

Conflict of Interests

The authors have no conflict of interests to declare.

\section{Acknowledgments}

The present study was financed in part by the São Paulo Research Foundation (FAPESP, in the Portuguese acronym).

\section{References}

1 Bulun SE. Endometriosis. N Engl J Med. 2009;360(03):268-279. Doi: 10.1056/NEJMra0804690

2 Crispi CP, Oliveira FMM, Damian JC Junior, Oliveira MAP. Endometriose. In: Crispi CP, Oliveira FMM, Damian JC Junior, Oliveira MAP. Tratado de videoendoscopia e cirurgia minimamente invasiva em ginecologia. 2a ed. Rio de Janeiro: Revinter; 2007:295-327

3 Fourquet J, Gao X, Zavala D, Orengo JC, Abac S, Ruiz A, et al. Patients' report on how endometriosis affects health, work, and daily life. Fertil Steril. 2010;93(07):2424-2428. Doi: 10.1016/j.fertnstert. 2009.09.017

4 Nnoaham KE, Hummelshoj L, Webster P, d'Hooge T, de Cicco Nardone F, de Cicco Nardone C, et al; World Endometriosis Research Foundation Global Study of Women's Health consortium. Reprint of: Impact of endometriosis on quality of life and work productivity: a multicenter study across ten countries. Fertil Steril. 2019;112(4S1, Suppl 1)e137-e152. Doi: 10.1016/j.fertnstert.2019.08.082

5 The Whoqol Group. The development of the World Health Organization quality of life assessment instrument (the WHOQOL). In: Orley J, Kuyken W, editors. Quality of life assessment: international perspectives: proceedings of the joint-meeting organized by the World Health Organization and the Fondation IPSEN in Paris, July 2-3, 1993. BerlinSpringer1994:41-57

6 Sepulcri RdeP, do Amaral VF. Depressive symptoms, anxiety, and quality of life in women with pelvic endometriosis. Eur J Obstet Gynecol Reprod Biol. 2009;142(01):53-56. Doi: 10.1016/j. ejogrb.2008.09.003

7 Holoch KJ, Lessey BA. Endometriosis and infertility. Clin Obstet Gynecol. 2010;53(02):429-438. Doi: 10.1097/GRF.0b013e3181 db7d71

8 Souza CA, Oliveira LM, Scheffel C, Genro VK, Rosa V, Chaves MF, Cunha Filho JS. Quality of life associated to chronic pelvic pain is independent of endometriosis diagnosis-a cross-sectional survey. Health Qual Life Outcomes. 2011;9:41. Doi: 10.1186/1477-7525-9-41

9 Dunselman GAJ, Vermeulen N, Becker C, Calhaz-Jorge C, D'Hooge T, De Bie B, et al; European Society of Human Reproduction and Embryology. ESHRE guideline: management of women with endometriosis. Hum Reprod. 2014;29(03):400-412. Doi: 10.1093/humrep/det457

10 Ferrero S, Abbamonte LH, Giordano M, Ragni N, Remorgida V. Deep dyspareunia and sex life after laparoscopic excision of endometriosis. Hum Reprod. 2007;22(04):1142-1148. Doi: 10.1093/humrep/del465

11 Ribeiro PAAG, Sekula VG, Abdalla-Ribeiro HSA, Rodrigues FC, Aoki T, Aldrighi JM. Impact of laparoscopic colorectal segment resection on quality of life in women with deep endometriosis: one year follow-up. Qual Life Res. 2014;23(02):639-643. Doi: 10.1007/s11136-013-0481-y

12 Silveira da Cunha Araújo R, Abdalla Ayroza Ribeiro HS, Sekula VG, da Costa Porto BT, Ayroza Galvão Ribeiro PA. Long-term outcomes on quality of life in women submitted to laparoscopic treatment for bowel endometriosis. J Minim Invasive Gynecol. 2014;21(04): 682-688. Doi: 10.1016/j.jmig.2014.02.005

13 Florentino AVA, Pereira AMG, Martins JA, Lopes RGC, Arruda RM. Quality of life assessment by the endometriosis health profile(EHP30) questionnaire prior to treatment for ovarian endometriosis in 
Brazilian women. Rev Bras Ginecol Obstet. 2019;41(09):548-554. Doi: 10.1055/s-0039-1693057

14 Vannuccini S, Reis FM, Coutinho LM, Lazzeri L, Centini G, Petraglia F. Surgical treatment of endometriosis: prognostic factors for better quality of life. Gynecol Endocrinol. 2019;35(11):1010-1014. Doi: 10.1080/09513590.2019.1616688

15 Comptour A, Pereira B, Lambert C, Chauvet P, Grémeau AS, Pouly $\mathrm{JL}$, et al. Identification of predictive factors in endometriosis for improvement in patient quality of life. J Minim Invasive Gynecol. 2019:S1553-4650(19)30227-4

16 Rush G, Misajon R, Hunter JA, Gardner J, O'Brien KS. The relationship between endometriosis-related pelvic pain and symptom frequency, and subjective wellbeing. Health Qual Life Outcomes. 2019;17(01):123. Doi: 10.1186/s12955-019-1185-y

17 Marqui ABT. [Use of questionnaires for evaluation of the quality of life in endometriosis]. Rev Bras Qual Vida.. 2014;6(02):104-114. Doi: 10.3895/S2175-08582014000200005

18 Cagnacci A, Della Vecchia E, Xholli A. Chronic pelvic pain improvement: impact on quality of life and mood. Gynecol Endocrinol. 2019;35(06):502-505. Doi: 10.1080/09513590.2018.1540571

19 de Freitas Fonseca M, Aragao LC, Sessa FV, Dutra de Resende JA Jr, Crispi CP. Interrelationships among endometriosis-related pain symptoms and their effects on health-related quality of life: a sectional observational study. Obstet Gynecol Sci. 2018;61(05): 605-614. Doi: 10.5468/ogs.2018.61.5.605

20 Martinez JE, Grassi DC, Marques LG. Análise da aplicabilidade de três instrumentos de avaliação de dor em distintas unidades de atendimento: ambulatório, enfermaria e urgência. Rev Bras Reumatol. 2011;51(04):304-308. Doi: 10.1590/S0482-50042011000400002

21 Jones G, Kennedy S, Barnard A, Wong J, Jenkinson C. Development of an endometriosis quality-of-life instrument: The Endometriosis Health Profile-30. Obstet Gynecol. 2001;98(02):258-264. Doi: 10.1016/s0029-7844(01)01433-8

22 Mengarda CV, Passos EP, Picon P, Costa AF, Picon PD. [Validation of Brazilian Portuguese version of quality of life questionnaire for women with endometriosis (Endometriosis Health Profile Questionnaire-EHP-30)]. Rev Bras Ginecol Obstet. 2008;30(08): 384-392. Doi: 10.1590/S0100-72032008000800003

23 Ware JEJr, Sherbourne CD. The MOS 36-item short-form health survey (SF-36). I. Conceptual framework and item selection. Med Care. 1992; 30(06):473-483. Doi: 10.1097/00005650-199206000-00002

24 Ciconelli RM, Ferraz MB, Santos W, Meinão I, Quaresma MR. Tradução para a língua portuguesa e validação do questionário genérico de avaliação de qualidade de vida SF-36 (Brasil SF-36). Rev Bras Reumatol. 1999;39(03):143-150

25 Browner WS, Newman TB, Hulley SB. Estimating sample size and power: applications and examples. In: Hulley SB, Cummings SR, Browner WS, Grady DG, Newman TB. Designing clinical research. 3rd ed. Philadelphia: Lippincott, Williams \& Wilkins; 2007:65-96

26 Leonardo-Pinto JP, Benetti-Pinto CL, Cursino K, Yela DA. Dienogest and deep infiltrating endometriosis: The remission of symptoms is not related to endometriosis nodule remission. Eur J Obstet Gynecol Reprod Biol. 2017;211:108-111. Doi: 10.1016/j.ejogrb.2017.02.015

27 Marinho MCP, Magalhaes TF, Fernandes LFC, Augusto KL, Brilhante AVM, Bezerra LRPS. Quality of life in women with endometriosis: an integrative review. J Womens Health (Larchmt). 2018;27(03): 399-408. Doi: 10.1089/jwh.2017.6397

28 Márki G, Bokor A, Rigó J, Rigó A. Physical pain and emotion regulation as the main predictive factors of health-related quality of life in women living with endometriosis. Hum Reprod. 2017;32 (07):1432-1438. Doi: 10.1093/humrep/dex091

29 Vercellini P, Barbara G, Abbiati A, Somigliana E, Viganò P, Fedele L. Repetitive surgery for recurrent symptomatic endometriosis: what to do? Eur J Obstet Gynecol Reprod Biol. 2009;146(01): 15-21. Doi: 10.1016/j.ejogrb.2009.05.007

30 Moradi M, Parker M, Sneddon A, Lopez V, Ellwood D. Impact of endometriosis on women's lives: a qualitative study. BMC Womens Health. 2014;14:123. Doi: 10.1186/1472-6874-14-123

31 Facchin F, Barbara G, Saita E, et al. Impact of endometriosis on quality of life and mental health: pelvic pain makes the difference. J Psychosom Obstet Gynaecol. 2015;36(04):135-141. Doi: 10.3109/0167482X.2015.1074173

32 Lorençatto C, Vieira MJN, Marques A, Benetti-Pinto CL, Petta CA. [Evaluation of pain and depression in women with endometriosis after a multi- professional group intervention]. Rev Assoc Med Bras (1992). 2007;53(05):433-438. Doi: 10.1590/S0104-423020 07000500020

33 Verket NJ, Uhlig T, Sandvik L, Andersen MH, Tanbo TG, Qvigstad E. Health-related quality of life in women with endometriosis, compared with the general population and women with rheumatoid arthritis. Acta Obstet Gynecol Scand. 2018;97(11):1339-1348. Doi: 10.1111/aogs.13427

34 Caruso S, Iraci M, Cianci S, Vitale SG, Fava V, Cianci A. Effects of longterm treatment with Dienogest on the quality of life and sexual function of women affected by endometriosis-associated pelvic pain. J Pain Res. 2019;12:2371-2378. Doi: 10.2147/JPR.S207599 